\title{
Pressure-induced polymerization of phenoxyethyl acrylate
}

\author{
K Kaminski ${ }^{1}$, R Wrzalik ${ }^{1}$, M Paluch ${ }^{1}, \mathrm{~J} \mathrm{Zioło}^{1}$ and C M Roland ${ }^{2}$ \\ ${ }^{1}$ Institute of Physics, Silesian University, Uniwersytecka 4, 40-007 Katowice, Poland \\ ${ }^{2}$ Naval Research Laboratory, Chemistry Division, Code 6120, Washington, \\ DC 20375-5342, USA
}

Received 4 March 2008

Published 29 May 2008

Online at stacks.iop.org/JPhysCM/20/244121

\begin{abstract}
Polymerization of phenoxyethyl acrylate was induced without catalyst or initiators by the application of hydrostatic pressure at elevated temperature. Broadband dielectric and infrared spectroscopy were employed to follow the course of the reaction, which reached a degree of conversion of $60 \%$. The structure of the obtained polymer was determined from density functional theory calculations.
\end{abstract}

(Some figures in this article are in colour only in the electronic version)

\section{Introduction}

Polymers are materials of enormous importance in various industries (food, pharmaceutical, medical, construction, electrical, etc). Often this is due to the performance advantages in comparison to more traditional materials, although the latter are often more costly as well. The demand for polymers has led to efforts to develop improved synthetic methods. Conventional polymerization relies on catalystpromoted thermal activation, irradiation, oxidation, etc [1-3], although alternative methods are used $[4,5]$. One promising approach is polymerization induced only by the application of large hydrostatic pressure. This method has obvious advantages: (i) the product tends to be of high purity; (ii) waste and toxicity aspects of catalysts are avoided; (iii) the reaction is performed in bulk without solvents; and (iv) potentially materials can be made that are unattainable at ambient pressure. There have been a few publications describing pressure-induced polymerization in unsaturated, hydrocarbons such as ethylene [6, 7], propylene [8], benzene [9, 10], isoprene [11, 12], styrene [13], and butadiene [2, 14]. In the case of ethylene, isoprene, and butadiene, laser irradiation of the system under high pressure can lead to new reaction pathways, producing unique polymer products. Nevertheless, further studies are required to clarify the reaction mechanisms, so that new syntheses can be developed and exploited.

In this paper we describe polymerization of the phenoxyethyl acrylate. Acrylate polymers, found in many different applications, are conventionally synthesized at high temperatures with catalysts or, in the case of free radical polymerization, with organic peroxides [15-18]. The only example of pressure-induced polymerization was earlier work of our group on tetraethylene glycol dimethacrylate (TEGDMA) polymerization [19]. In that case, the reaction was accompanied by significant crosslinking, leading to a network structure in the obtained polymer. With phenoxyethyl acrylate only linear polymerization is possible, since unlike TEGDMA phenoxyethyl acrylate has only one double bonds.

The main techniques used in our investigation were dielectric and infrared (IR) spectroscopy. The first is commonly used to measure the dynamics of polymers. It can be also used to monitor polymerization, since during the reaction there is a decrease of the dc conductivity due to reduced diffusivity of ions. Simultaneously there is an increase in the local segmental $(\alpha-)$ relaxation time of the main species due to its increasing size and more constrained nature. This means that the glass transition temperature, $T_{\mathrm{g}}$, of the reacting system also increases during polymerization. IR spectroscopy allows the identification of the reaction products, as well as the moieties involved in the polymerization, which is informative concerning the reaction mechanism.

\section{Experimental details}

The phenoxyethyl acrylate (98\% purity) was received from Sartomer Company. Polymerization. Briefly, the procedure involved filling the dielectric cell with the monomer liquid, and then placing it into a Teflon bellows mounted in the high pressure chamber. Hydrostatic pressure was generated 


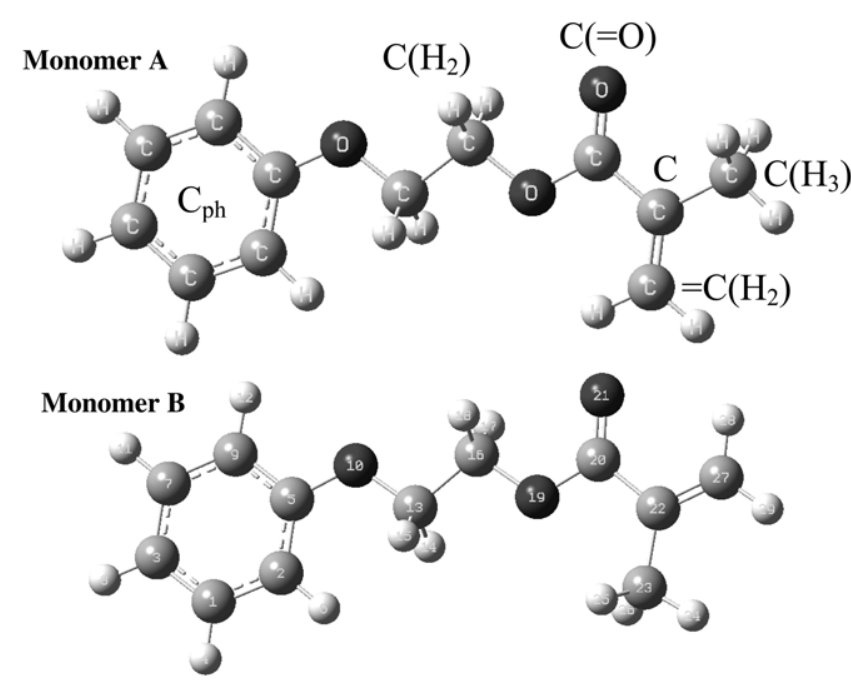

Scheme 1. Structure of monomer A and monomer B with atom numbering and symbols used in table 1 .

by displacing a piston via a hydraulic press. Pressure was calculated from the force exerted on the piston (accuracy $\sim 10 \mathrm{MPa}$ ).

IR measurements used a Bio-Rad FTS-6000 spectrometer equipped with a $\mathrm{KBr}$ beam splitter, a standard source, and a DTGS Peltier-cooled detector. The MIRacle diamond accessory with a KRS5 prism was used to collect spectra in the range $380-4000 \mathrm{~cm}^{-1}$ with $2 \mathrm{~cm}^{-1}$ resolution. Generally 32 scans were accumulated to achieve sufficient quality spectra.

\section{Calculations}

$A b$ initio calculations were performed with the PQS program. Geometry optimization and IR spectra were calculated using density functional theory (DFT); the B3LYP functional and standard Gaussian polarized and split-valence basis set (6$\left.31 \mathrm{G}^{*}\right)$ were applied. The harmonic vibrational frequencies and IR intensities were recalculated using Pulay's scaled quantum mechanical force field (SQM) methodology [20]. This procedure gives good reproduction of the fundamental frequencies and allows band assignments.

The calculations were done for two conformers of the phenoxyethyl acrylate molecule (monomer A and B) and the polymer derived from four monomers, as seen in schemes 1 and 2, respectively. To compare the theoretical and experimental results more easily, the theoretical spectra were constructed as a sum of Lorentz bands with $5 \mathrm{~cm}^{-1}$ full width at half-maximum.

\section{Results and discussion}

An initial pressure of $1 \mathrm{GPa}$ was applied at $T=373 \mathrm{~K}$. During the reaction a significant drop in pressure was observed, since polymerization reduces the volume of the material. The recovered product had a rubber-solid form, clear evidence that the liquid monomer had polymerized.

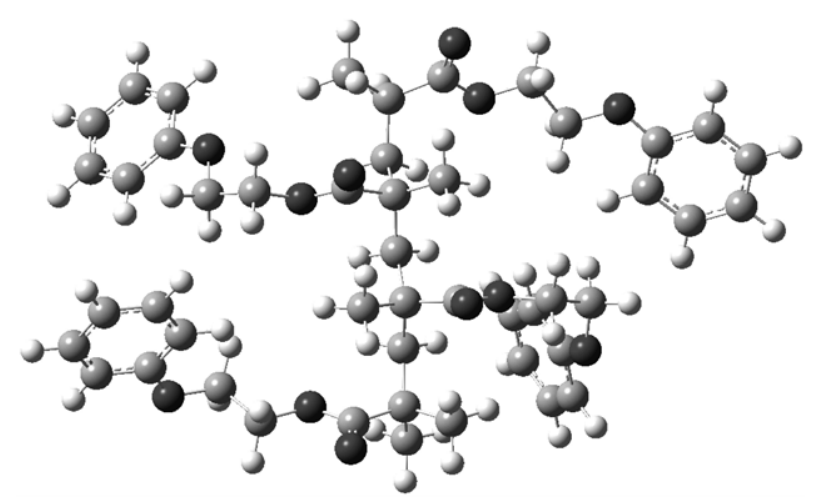

Scheme 2. Structure of the polymer composed of four phenoxyethyl acrylate monomers.

In figure 1 are shown the dielectric loss spectra of the monomer (left upper panel) and polymer after $15 \mathrm{~h}$ reaction (right upper panel). The spectra are above $T_{\mathrm{g}}$, defined as the temperature at which $\tau_{\alpha}=100 \mathrm{~s}$. For both materials a primary $\alpha$-relaxation process and the dc conductivity are evident in the spectra; these move toward lower frequencies with decreasing temperature. In addition a secondary relaxation process becomes apparent at lower temperatures for both monomer and product.

In the lower panel of figure 1 representative loss spectra of the monomer and polymer measured respectively at $T=215$ and $211 \mathrm{~K}$ and at $T=297$ and $285 \mathrm{~K}$ are shown (note the dc conductivity was subtracted for clarity). At these temperatures the polymer and monomer have the same $\tau_{\alpha}$. The shifting of $\tau_{\alpha}$ to higher temperature reflects the larger molecular weight of the product. The width of the $\alpha$-relaxation peak of the polymer is also broader than that of the monomer, in addition to some broadening with decreasing temperature. The loss spectra for the polymer also has a significantly greater dc contribution. This may originate from unreacted monomers. Note that in the range of temperatures where the $\alpha$-relaxation of the polymer is observed, there is a large dc conductivity in the loss spectrum of the phenoxyethyl acrylate.

In figure 2 the temperature dependence of the $\alpha$-relaxation times of polymer and monomer are compared. $\tau_{\alpha}(T)$ data were fitted by the VFT equation:

$$
\tau_{\alpha}=\tau_{\mathrm{VFT}} \exp \left[D /\left(T-T_{0}\right)\right],
$$

from which the glass transition temperatures were determined, equal to 194 and $245 \mathrm{~K}$ for the monomer and polymer respectively. Of course, $T_{\mathrm{g}}$ is larger for the polymer than the corresponding monomer $[21,22]$. The large difference $(50 \mathrm{~K})$ in the present case suggests the product has a substantial molecular weight.

The fragilities of the monomer and polymer were determined as:

$$
m=\mathrm{d} \log _{10} \tau_{\alpha} /\left.\mathrm{d}\left(T_{\mathrm{g}} / T\right)\right|_{\left(T_{\mathrm{g}} / T\right)=1}
$$

with the surprising result that $m=46$ for the polymer, a small value and much less than for the monomer, $m=$ 79. Below the high polymer limit fragility increases with 

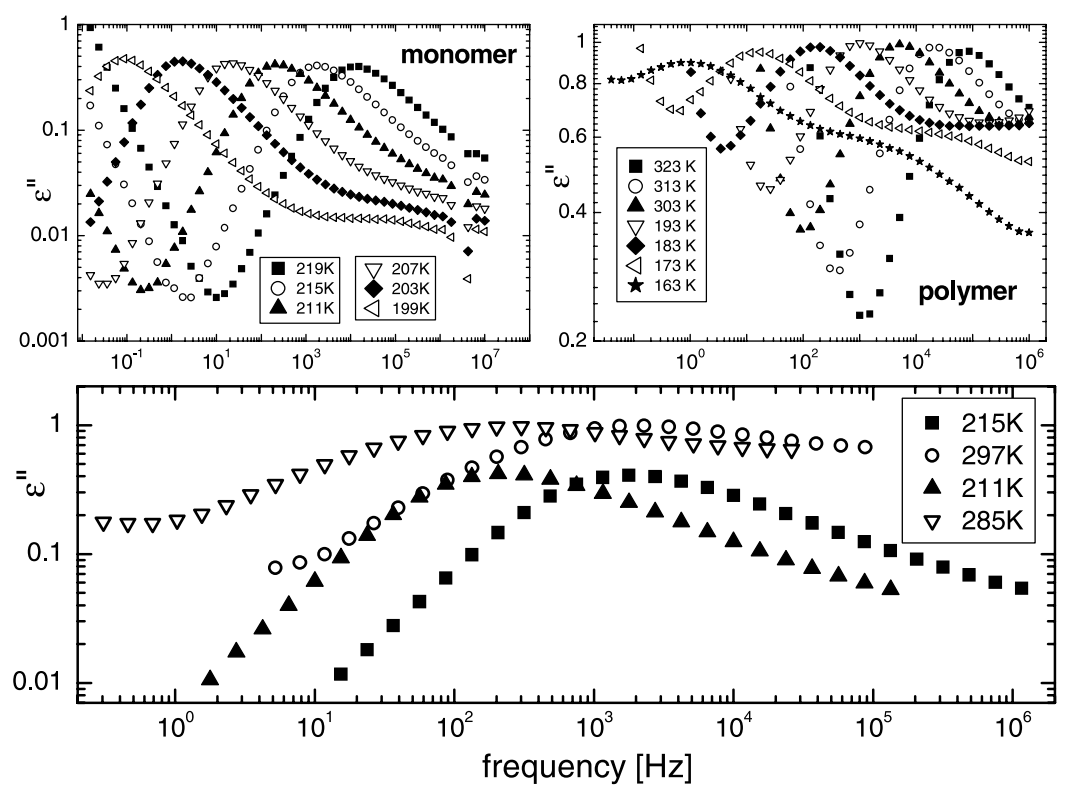

Figure 1. Left and right upper panels: dielectric loss curves for monomer and polymer at $0.1 \mathrm{MPa}$. Lower panel: dielectric loss spectra of the monomer measured at $T=215$ and $211 \mathrm{~K}$ (filled symbols) and the polymer at $T=297$ and $285 \mathrm{~K}$ (open symbols). The dc conductivity has been subtracted.

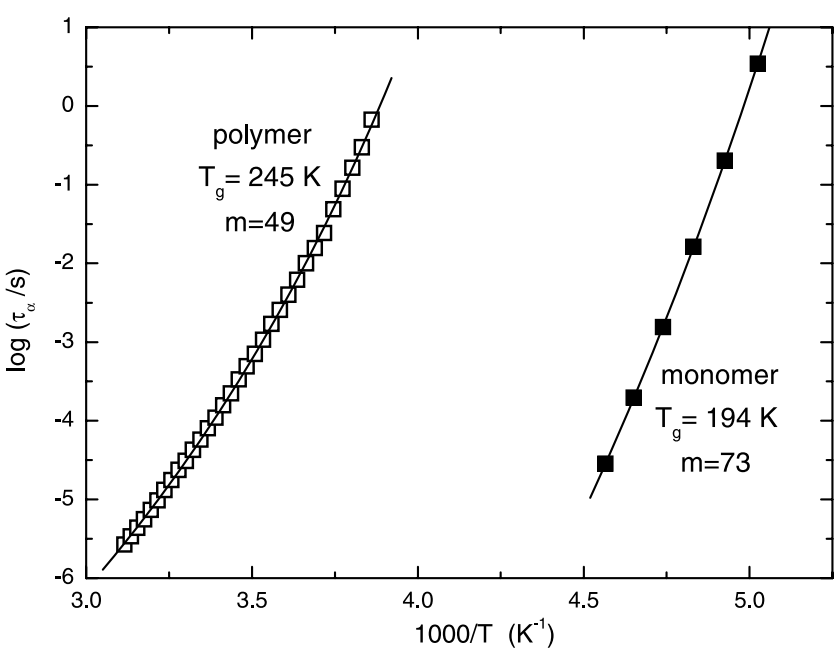

Figure 2. Arrhenius plot of the dielectric $\alpha$-relaxation times for the phenoxyethyl acrylate (filled squares) and polymer (open squares). The solid lines are VFT fits.

molecular weight [22]. The only exception is polyisobutylene, for which was shown recently that over a range of molecular weight, $m$ decreases with molecular weight [23]. We speculate that the peculiar result herein is due to steric hindrance of the polymer. As can be seen in scheme 2, the geometry of the polymer, composed by phenoxyethyl acrylate monomer units, is rather complex.

To summarize this part of the work, dielectric measurements show that phenoxyethyl acrylate undergoes polymerization to a substantial molecular weight at $1 \mathrm{GPa}$ and $373 \mathrm{~K}$. Next we focus on IR measurements to describe the structure of the polymer and estimate the degree of conversion. FTIR spectra of the phenoxyethyl acrylate monomer and polymer are shown

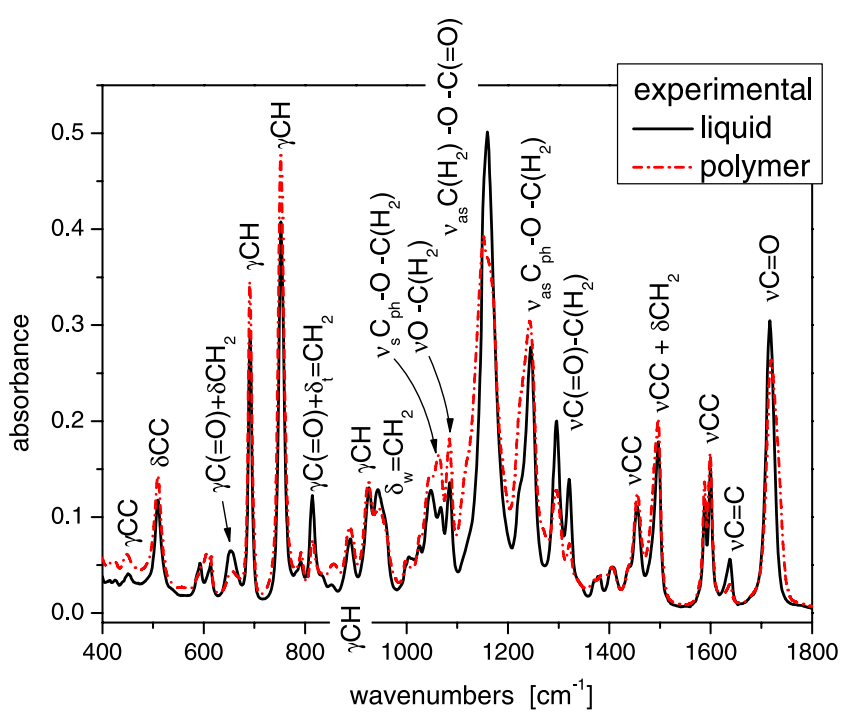

Figure 3. IR spectra of the phenoxyethyl acrylate (solid line) and polymer (dotted line) showing the vibrational assignments.

in figure 3. The spectra are rather similar, although differences are present. The most important changes are for the bands at $1637,1321,1286,1151,1064,945,814$, and $656 \mathrm{~cm}^{-1}$. To assign the fundamental vibrations of these absorptions, DFT vibrational spectra calculations were carried out.

As depicted in figure 4, the calculated IR spectra for the phenoxyethyl acrylate monomer (upper curves) reproduces well the position of the bands. However, in the frequency range $1370-1230 \mathrm{~cm}^{-1}$ two peaks are observed for the experimental spectra, whereas there is only one in the calculated spectra. To investigate this we made additional calculations for the monomer with antiparallel alignment of 


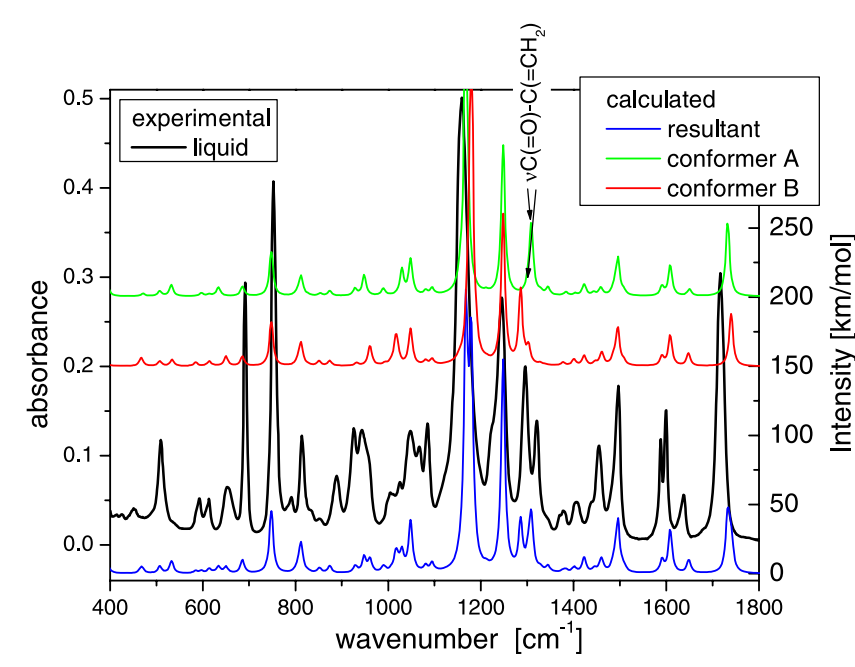

Figure 4. Calculated IR spectrum for monomer A (green solid line) and B (red solid line), sum of the two calculated spectra (blue solid line), and experimental spectrum of the phenoxyethyl acrylate (black solid line).

the $\mathrm{C}=\mathrm{O}$ and $\mathrm{C}=\mathrm{C}$ bonds (see scheme 1); the energy of this conformer (monomer B) is only $0.097 \mathrm{kcal} \mathrm{mol}^{-1}$ higher than for monomer $\mathrm{A}$. As can be seen in figure 4, interaction between $\mathrm{C}=\mathrm{O}$ and $\mathrm{C}=\mathrm{CH}_{2}$ groups shifts the frequency of the $\nu \mathrm{C}(=\mathrm{O})-\mathrm{C}\left(=\mathrm{CH}_{2}\right)$ mode from $1286 \mathrm{~cm}^{-1}$ for monomer A to $1310 \mathrm{~cm}^{-1}$ for monomer $\mathrm{B}$. The implication is that the peaks at 1321 and $1286 \mathrm{~cm}^{-1}$ are due to the stretching vibration $v \mathrm{C}(=\mathrm{O})-\mathrm{C}\left(=\mathrm{CH}_{2}\right)$ of these two conformers. Assuming a Boltzmann distribution we calculated the spectrum as a sum of two components (assuming a weighting of 0.86 for monomer B). This yields much better agreement between the theoretical (blue curve in figure 4) and experimental data, indicating that both monomers are present in the monomer.

In figure 5 the theoretical spectrum calculated for an oligomer composed of four monomers (scheme 2 ) is compared to the experimental measurements on the polymer. The agreement is generally good, although some differences are evident. These are expected since the calculations were made for isolated molecules and the oligomer is approximated by only four monomers. Note that calculated spectra (not shown) for oligomers with only two or three repeat units gave worse agreement. Unfortunately, the required computational time increases with the degree of polymerization.

The decrease in the intensity of the $\mathrm{C}=\mathrm{C}$ stretching bond (at $1637 \mathrm{~cm}^{-1}$ for phenoxyethyl acrylate) provides a measure of the extent of the polymerization. However, since the experimental spectra were obtained using the attenuated total reflection technique, a direct comparison of the band intensities for the monomer and polymer cannot be made, since the materials differ in refractive index and thus penetration depth of the IR beam. Thus, we renormalized the intensity assuming that the integral intensities of the aromatic carbon stretching vibrations, at 1600 and $1588 \mathrm{~cm}^{-1}$, are equal for the liquid and polymer sample (the phenyl ring is not involved in the polymerization reaction). The integral intensity ratios, $R=I_{\text {polymer }} / I_{\text {liquid, }}$ are listed in table 1 , showing that

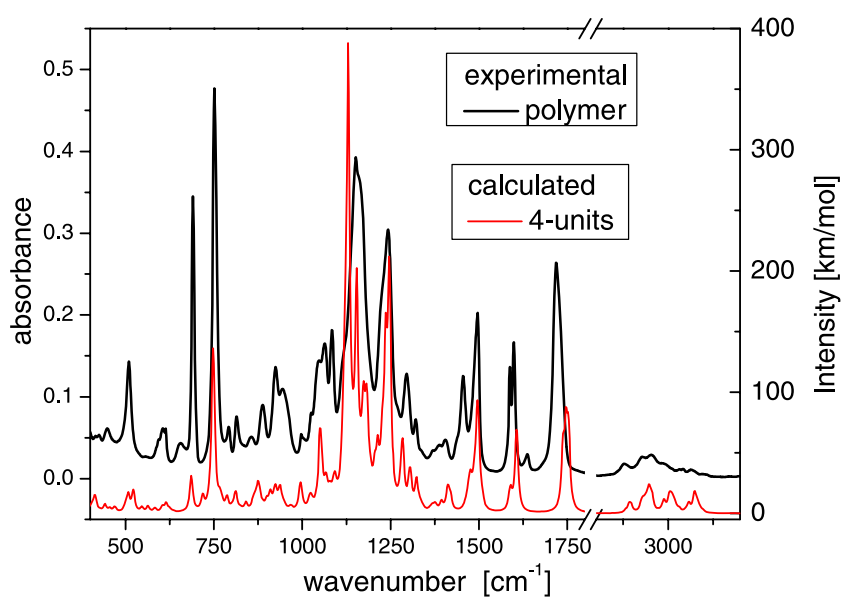

Figure 5. Calculated (red solid line) and experimental (black solid line) IR spectra of the polymer.

for moieties inactive during polymerization, the normalized intensities are equal: for the benzene ring $\mathrm{CC}$ vibrations ( $\nu \mathrm{CC}$ at $1455 \mathrm{~cm}^{-1}$ and $\gamma \mathrm{CC}$ at $509 \mathrm{~cm}^{-1}$ ), this ratio is very close to unity. For $\gamma \mathrm{CH}$ benzene vibrations, at 752 and $691 \mathrm{~cm}^{-1}$, the ratio is slightly higher but within the experimental error. The intensity ratios of the $v_{\mathrm{as}} \mathrm{C}\left(\mathrm{H}_{2}\right)_{-}$ $\mathrm{O}-\mathrm{C}(=\mathrm{O})$ band at $1151 \mathrm{~cm}^{-1}$ and the $\nu \mathrm{C}=\mathrm{O}$ band at $1719 \mathrm{~cm}^{-1}$ are also unity, although for the polymer the peaks are much more asymmetrical than for the liquid. For the $\nu \mathrm{CC}$ band at $1496 \mathrm{~cm}^{-1}$ there is a substantial increase in the ratio, but this is due to the overlapping $\delta \mathrm{CH}_{2}$ vibration at $1487 \mathrm{~cm}^{-1}$. The situation is similar for the overlapping $v_{\mathrm{as}} \mathrm{C}_{\mathrm{ph}}-\mathrm{O}-\mathrm{C}\left(\mathrm{H}_{2}\right)$ band at $1243 \mathrm{~cm}^{-1}$ and the $\delta \mathrm{CH}_{2}$ peak at $1220 \mathrm{~cm}^{-1}$.

We can conclude that renormalization of the spectra allows the extent of the reaction to be quantified. The result is that $\sim 60 \%$ of the double bonds reacted during polymerization at $1 \mathrm{GPa}$ and $373 \mathrm{~K}$. The decreased intensity in the polymer spectrum is seen for the $\mathrm{C}=\mathrm{C}$ stretching vibration at $1637 \mathrm{~cm}^{-1}$, as well as the bands at 1321, 1295, 852, and $656 \mathrm{~cm}^{-1}$. All these bands arise from vibrations involving the unsaturated carbons (see table 1).

Interestingly, the IR band at $814 \mathrm{~cm}^{-1}$ increases in intensity by more than a factor of three during the polymerization. Our calculations indicate that it corresponds to skeletal vibrations of the chain backbone. This result suggests that a significant degree of polymerization was achieved.

\section{Conclusion}

Polymerization of phenoxyethyl acrylate was induced by a hydrostatic pressure of $1 \mathrm{GPa}$ and $373 \mathrm{~K}$, yielding a polymer with a substantial molecular weight. The conversion was about $60 \%$, which compares favorably to industrial scale polymerizations, which yield conversions for common plastics such as polyethylene, polypropylene, and polymethylmethacrylate in the range from 5 to $10 \%$. The fragility, or sensitivity of the segmental dynamics to temperature, is lower for the polymer than for the monomer. 
Table 1. Comparison of the calculated and experimental vibrational frequencies for the monomer and polymer.

\begin{tabular}{|c|c|c|c|c|}
\hline \multicolumn{3}{|c|}{ Frequencies $\left(\mathrm{cm}^{-1}\right)$} & \multirow[b]{3}{*}{ Description $^{\mathrm{a}}$} & \multirow[b]{3}{*}{ Ratio } \\
\hline \multirow{2}{*}{$\begin{array}{l}\text { Calculated } \\
\text { liquid }\end{array}$} & \multicolumn{2}{|c|}{ Experimental } & & \\
\hline & Liquid & Polymer & & \\
\hline 1732 & 1719.0 & 1716.7 & $v \mathrm{C}=\mathrm{O}$ & 1.00 \\
\hline 1650 & 1637.3 & 1637.8 & $v \mathrm{C}=\mathrm{C}$ & 0.40 \\
\hline 1609 & 1598.9 & 1599.0 & $v \mathrm{CC}(8 \mathrm{a})$ & $100^{\mathrm{b}}$ \\
\hline 1590 & 1587.8 & 1588.2 & $\nu \mathrm{CC}(8 \mathrm{~b})$ & $1.00^{\circ}$ \\
\hline 1496 & 1495.8 & 14967 & $v \mathrm{CC}(19 \mathrm{a})+\delta \mathrm{CH}_{2}$ & 1.18 \\
\hline 1487 & & & $\delta_{\mathrm{s}} \mathrm{CH}_{2}$ & \\
\hline 1458 & 1455.5 & 1454.3 & $\nu C C(19 b)$ & 1.06 \\
\hline 1423 & 1405.0 & 1406.1 & $\delta_{\mathrm{w}} \mathrm{CH}_{2}$ & \\
\hline 1310 & 1321.2 & 1320.7 & $\begin{array}{l}\nu \mathrm{C}(=\mathrm{O})-\mathrm{C}\left(=\mathrm{CH}_{2}\right)+\nu \mathrm{C}\left(=\mathrm{CH}_{2}\right)-\mathrm{C}\left(\mathrm{H}_{3}\right)(\mathrm{A}) \\
\delta \mathrm{CH}(3)\end{array}$ & 0.64 \\
\hline 1286 & 1295.4 & $\overline{1295.8}$ & $\begin{array}{l}\nu \mathrm{C}(=\mathrm{O})-\mathrm{C}\left(=\mathrm{CH}_{2}\right)+\nu \mathrm{C}\left(=\mathrm{CH}_{2}\right)-\mathrm{C}\left(\mathrm{H}_{3}\right)(\mathrm{B}) \\
\nu \mathrm{C}(=\mathrm{O})-\mathrm{C}\left(-\mathrm{CH}_{2}-\right)\end{array}$ & \\
\hline 1248 & 1243.1 & 1245.1 & $v_{\mathrm{as}} \mathrm{C}_{\mathrm{ph}}-\mathrm{O}-\mathrm{C}\left(\mathrm{H}_{2}\right)$ & 1.21 \\
\hline 1211 & $\sim 1220$ & $\sim 1220$ & $\delta \mathrm{CH}_{2}$ & \\
\hline 1168 & 1151.4 & 1159.2 & $v_{\mathrm{as}} \mathrm{C}\left(\mathrm{H}_{2}\right)-\mathrm{O}-\mathrm{C}(=\mathrm{O})$ & 1.00 \\
\hline $\begin{array}{l}1095 \\
1080\end{array}$ & 1084.3 & 1085.1 & $\begin{array}{l}\nu \mathrm{O}-\mathrm{C}\left(\mathrm{H}_{2}\right)+\nu \mathrm{C}\left(\mathrm{H}_{2}\right)-\mathrm{C}\left(\mathrm{H}_{2}\right)+\delta \mathrm{O}-\mathrm{C}\left(\mathrm{H}_{2}\right)-\left(\mathrm{H}_{2}\right) \\
\delta \mathrm{CH}(18 \mathrm{~b})\end{array}$ & \\
\hline 1048 & 1063.7 & 1067.3 & $v \mathrm{O}-\mathrm{C}\left(\mathrm{H}_{2}\right)+v \mathrm{C}\left(\mathrm{H}_{2}\right)-\mathrm{C}\left(\mathrm{H}_{2}\right)$ & \\
\hline 1030 & 1025.5 & 1026.0 & $v_{\mathrm{s}} \mathrm{C}_{\mathrm{ph}}-\mathrm{O}-\mathrm{C}\left(\mathrm{H}_{2}\right)$ & \\
\hline 990 & - & 997.4 & $\nu \mathrm{CC}(13)$ & \\
\hline 948 & 944.6 & 943.2 & $\delta_{\mathrm{w}}=\mathrm{CH}_{2}$ & \\
\hline 928 & 924.3 & 925.9 & $\gamma \mathrm{CH}(17 \mathrm{a})$ & \\
\hline 874 & 888.0 & 889.0 & $\gamma \mathrm{CH}(17 b)$ & \\
\hline 853 & 851.6 & 856.4 & $v \mathrm{C}\left(\mathrm{H}_{2}\right)-\mathrm{C}\left(\mathrm{H}_{2}\right)-\mathrm{O}-\mathrm{C}(=\mathrm{O})-\mathrm{C}\left(\mathrm{H}_{3}\right)$ skeletal & 3.75 \\
\hline 812 & 814.4 & 813.9 & $\delta_{\mathrm{r}}=\mathrm{CH}_{2}$ & 0.35 \\
\hline 803 & 792.0 & 791.0 & $\delta_{\mathrm{t}}=\mathrm{C}\left(\mathrm{H}_{2}\right)+\gamma \mathrm{C}(=\mathrm{O})$ & \\
\hline 748 & 751.6 & 752.4 & $\gamma \mathrm{CH}(11)$ & 1.14 \\
\hline 686 & 690.8 & 691.1 & $\gamma \mathrm{CC}(4)$ & 1.09 \\
\hline 634 & 656.0 & 652.9 & $\gamma \mathrm{C}(=\mathrm{O})+\delta_{\mathrm{t}}=\mathrm{C}\left(\mathrm{H}_{2}\right)$ & 0.39 \\
\hline 614 & 613.4 & 613.3 & $\delta \mathrm{C}_{\mathrm{ph}}-\mathrm{O}-\mathrm{C}\left(\mathrm{H}_{2}\right)-\mathrm{C}\left(\mathrm{H}_{2}\right)$ skeletal & \\
\hline 597 & 592.4 & 592.1 & $\delta \mathrm{C}=\mathrm{O}+v \mathrm{C}(=\mathrm{O})-\mathrm{C}+v \mathrm{C}-\mathrm{C}\left(\mathrm{H}_{3}\right)$ & \\
\hline 507 & 509.5 & 509.4 & $\gamma \mathrm{CC}(16 \mathrm{~b})$ & 0.99 \\
\hline
\end{tabular}

${ }^{a}$ Atom description in figure 1; (A), (B)—monomer A and B; mode description: $v$-stretching, $\delta$-in-plane deformation, $\gamma$-out-of-plane deformation; $\delta \mathrm{CH}_{2}$ : s-scissoring, t-twisting, $\mathrm{r}$-rocking, $\mathrm{w}$ - wagging; s-symmetric, as - asymmetric; numbering of benzene ring vibration according to Wilson.

${ }^{\mathrm{b}}$ Peaks chosen for comparison of the experimental spectra.

This unusual property may be related to the complicated geometry of the polymer, as revealed by DFT calculations.

\section{Acknowledgments}

Financial support of the Committee for Scientific Research, Poland (KBN, Grant No. N202 130 32/3785) is gratefully acknowledged. The work at NRL was supported by the Office of Naval Research. We thank the Nordmann Company for providing the phenoxyethyl acrylate. K K acknowledges financial assistance from FNP (2008).

\section{References}

[1] Bhowmick A and Vijayabaskar V 2006 Rubber Chem. Technol. 79402

[2] Citroni M, Ceppatelli M, Bini R and Schettino V 2002 Science 29585505

[3] Chelazzi D, Ceppatelli M, Santoro M, Bini R and Schettino V 2004 Nature 3470

[4] Buter R, Tan Y Y and Challa G 1973 J. Polym. Sci. Polym. Chem. Edn 111003
[5] Serizawa T, Hamada K and Akashi M 2004 Nature 42952

[6] Chelazzi D, Ceppatelli M, Santoro M, Bini R and Schettino V 2004 Nature 3470

[7] Chelazzi D, Ceppatelli M, Santoro M, Bini R and Schettino V 2005 J. Phys. Chem. B 10921658

[8] Citroni M, Ceppatelli M, Bini R and Schettino V 2005 J. Chem. Phys. 123194510

[9] Ciabini L, Santoro M, Bini R and Schettino V 2002 Phys. Rev. Lett. 88085505

[10] Ciabini L, Santoro M, Gorelli F A, Bini R, Schettino V and Raugei S 2007 Nat. Mater. 639

[11] Citroni M, Ceppatelli M, Bini R and Schettino V 2007 J. Phys. Chem. B 1113910

[12] Abdi-Oskoui H, Jenner G and Brun O 1972 Makromol. Chem. 164149

[13] Gourdain D, Chervin J C and Pruzan Ph 1996 J. Chem. Phys. 1059040

[14] Citroni M, Ceppatelli M, Bini R and Schettino V 2003 J. Chem. Phys. 1181815

[15] Save M, Weavers J and Armes S 2002 Macromolecules 351152

[16] Nishikawa T, Ando T, Kamigaito M and Sawamoto M 1997 Macromolecules 302244 
[17] Matyjaszewski K, Wei M, Xia J and McDermott N E 1997 Macromolecules 308161

[18] Matyjaszewski K, Nakagawa A and Jasieczek C 1998 Macromolecules 311535

[19] Kaminski K, Paluch M, Wrzalik R, Ziolo J, Bogoslovov R and Roland C M 2008 J. Chem. Phys. submitted

[20] Baker J, Jarzecki A A and Pulay P 1998 J. Phys. Chem. A 1021412
[21] Ding Y, Novikov V N, Sokolov A P, Cailliaux A, Dalle-Ferrier C, Alba-Simionesco C and Frick B 2004 Macromolecules 379264

[22] Sokolov A P, Novikov V N and Ding Y 2007 J. Phys.: Condens. Matter 19205116

[23] Kunal K, Paluch M, Roland C M, Alba-Simionesco C, Puskas J E, Chen Y and Sokolov A P 2008 J. Polym. Sci. Polym. Phys. Edn at press 